Check for updates

Cite this: RSC Adv., 2019, 9, 37747

\title{
Molecular design and properties of bridged energetic pyridines derivatives $\dagger$
}

\author{
Diandian Zhai, (D) Jinpeng Wang, Lina Hao, Congming Ma, (D) * Peng Ma, (D) * \\ Yong Pan* and Juncheng Jiang
}

A series of bridged pyridine-based energetic derivatives were designed and their geometrical structures, electronic structures, heats of formation, detonation properties, thermal stabilities, thermodynamic properties and electrostatic potential were fully investigated using density functional theory. The results show that the steric hindrance effect is a decisive factor for structural stability, and the formation of intramolecular or intermolecular hydrogen bonds doesn't provide advantages to stabilize molecular structure, which was demonstrated by insertion of 3,4,5-trinitro- $1 \mathrm{H}$-pyrazole, 3,4-dinitro- $1 \mathrm{H}$-pyrazol-5amine, 3,5-dinitro- $1 \mathrm{H}$-pyrazol-4-amine and 3-nitro-1H-1,2,4-triazol-5-amine. The azide group and azo bridge play an important role in improving the heats of formation of energetic pyridine-based materials. All designed molecules were found to have values of density ranging from $1.70 \mathrm{~g} \mathrm{~cm}^{-3}$ (E6, F6) to $2.11 \mathrm{~g} \mathrm{~cm}^{-3}$ (D3), values of detonation velocity ranging from $7.1 \mathrm{~km} \mathrm{~s}^{-1}$ (F1) to $9.77 \mathrm{~km} \mathrm{~s}^{-1}$ (D8), and values of detonation pressure ranging from $21.5 \mathrm{GPa}$ (F1) to $46.0 \mathrm{GPa}$ (D8). When a $\mathrm{p}$ - $\pi$ conjugation formed between the nitrogen atom and pyridine ring, the bond between nitrogen and hydrogen atoms may be broken as the trigger bond.

Received 4th September 2019 Accepted 7th November 2019

DOI: $10.1039 / \mathrm{c} 9 \mathrm{ra} 07087 \mathrm{~g}$

rsc.li/rsc-advances
(TNPy), 2,4,6-trinitropydine-1-oxide (TNPyO) and 2,6-diamino3,5-dinitropyridine-1-oxide (ANPyO) in the twentieth century, illustrating that the density and thermal stability increase with an alternating array of amino- and nitro-groups. Zhao ${ }^{5}$ reported two promising heat-resistant energetic materials based on the pyridine and tetrazole ring were synthesized with a high decomposition temperature in excess of $300^{\circ} \mathrm{C}$. Recently, a kind of azo-bridged pyridine precursor was synthesized for the first time to develop new energetic pyridine-based compounds. ${ }^{6}$ Thus, this lead to the attempt to design and calculate bridged energetic pyridines derivatives (Scheme 1).

In this study, a systematic research on electronic structures, heats of formation (HOF), detonation properties, thermal stabilities and thermodynamic properties of bridged energetic carbon in the backbone to carbon dioxide. Meanwhile, due to their lower carbon and hydrogen content, some properties of high-nitrogen such as density and oxygen balance have distinct advantages over conventional energetic materials. ${ }^{2}$ As a result of these properties, scientists have designed and synthesized energetic azo materials with useful detonation properties. Licht and Ritter $^{3,4}$ reported the synthesis of 2,4,6-trinitropyridine

College of Safety Science and Engineering, Nanjing Tech University, Nanjing, Jiangsu, CN 211800, China. E-mail: maming1306@126.com; mpcctv@163.com; lh1083517594@gmail.com

$\dagger$ Electronic supplementary information (ESI) available: Computational methods, DFT/B3LYP/6-311G(d,p) optimized geometries of B9, B10, B11 and B12; the specific data of bond order for all designed compounds. See DOI: 10.1039/c9ra07087g pyridines derivatives ( such as $-\mathrm{C}=\mathrm{C}-,-\mathrm{NH}-\mathrm{NH}-$ and $-\mathrm{N}=\mathrm{N}-$ )

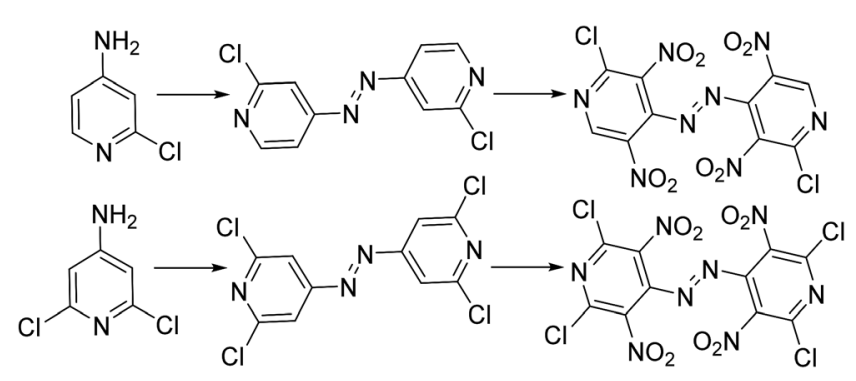

Scheme 1 Template reactions of energetic pyridine molecules. 

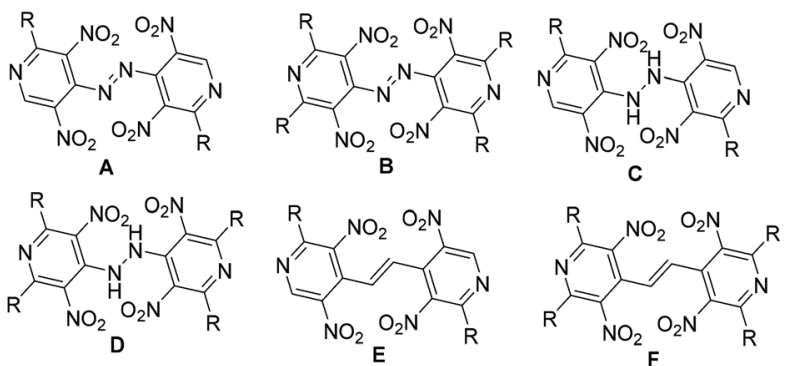

$\mathrm{R}=-\mathrm{CN}(1),-\mathrm{N}_{3}(2),-\mathrm{NF}_{2}(3),-\mathrm{NH}_{2}(4),-\mathrm{NHNO}_{2}(5),-\mathrm{NHNH}_{2}(6),-\mathrm{CH}\left(\mathrm{NO}_{2}\right)_{2}(7),-\mathrm{C}\left(\mathrm{NO}_{2}\right)_{3}(8)$

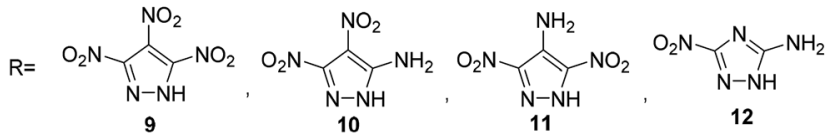

Scheme 2 Designed energetic molecules based on bridged pyridines. with various energetic groups (such as $-\mathrm{CN},-\mathrm{N}_{3},-\mathrm{NF}_{2},-\mathrm{NH}_{2}$, $\left.-\mathrm{NHNO}_{2},-\mathrm{NHNH}_{2},-\mathrm{CH}\left(\mathrm{NO}_{2}\right)_{2},-\mathrm{C}\left(\mathrm{NO}_{2}\right)_{3}\right)^{7}$ or common energetic materials containing active hydrogen atoms (such as 3,4,5-trinitro-1 $H$-pyrazole, 3,4-dinitro- $1 H$-pyrazol-5-amine, 3,5dinitro-1 $H$-pyrazol-4-amine, and 3-nitro- $1 \mathrm{H}$-1,2,4-triazol-5amine) were investigated (Scheme 2, series A-F). It is certain understanding of the physical and chemical properties of energetic pyridines.

\section{Results and discussion}

\subsection{Electronic structures}

The Highest Occupied Molecular Orbital (HOMO) and the Lowest Unoccupied Molecular Orbital (LUMO), which is called Frontier Molecular Orbital Theory (FMO Theory), has that all results will provide useful information for a better

Table 1 Calculated HOMO and LUMO energies (eV) and energy gaps ( $\triangle E_{\text {LUMO-HOMO }}$ ) of designed compounds






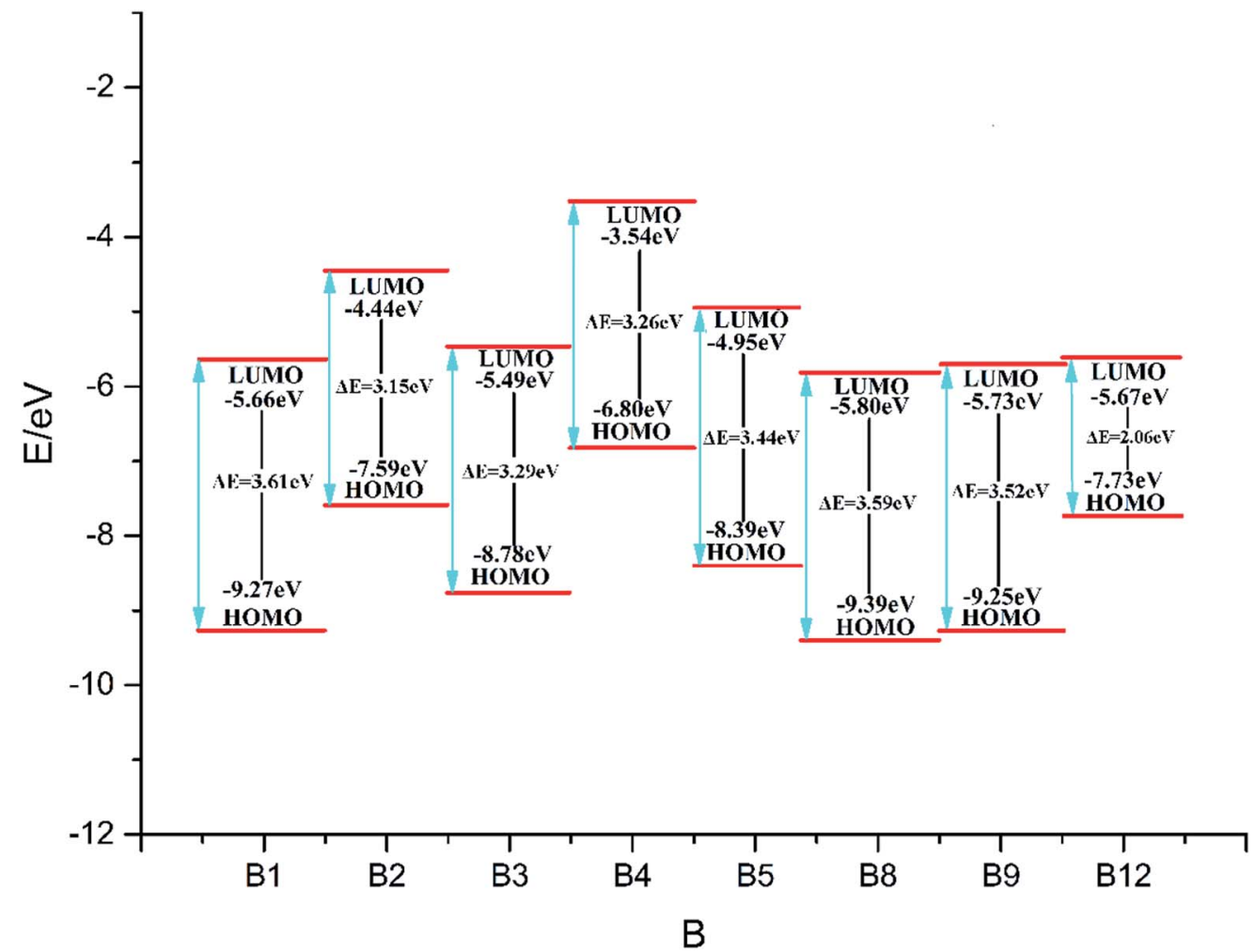

Fig. 1 The variation trends of $\Delta E_{\text {LUMO-HOMO }}$ of representative designed compounds.

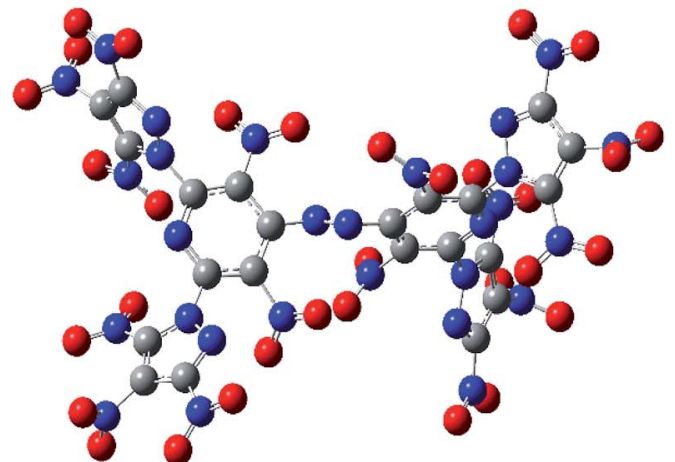

B9

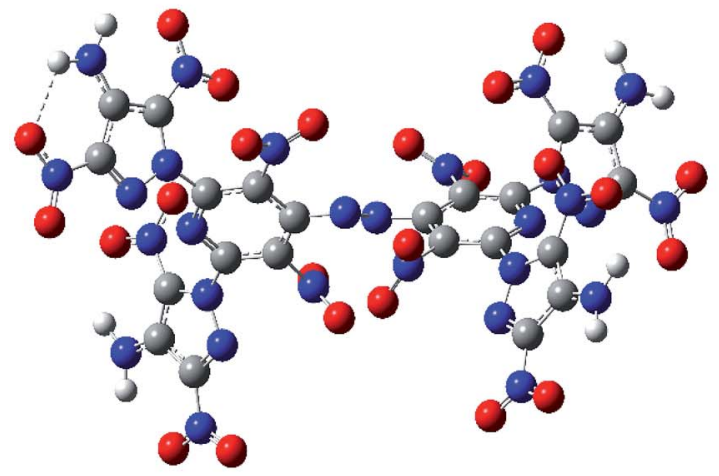

B11

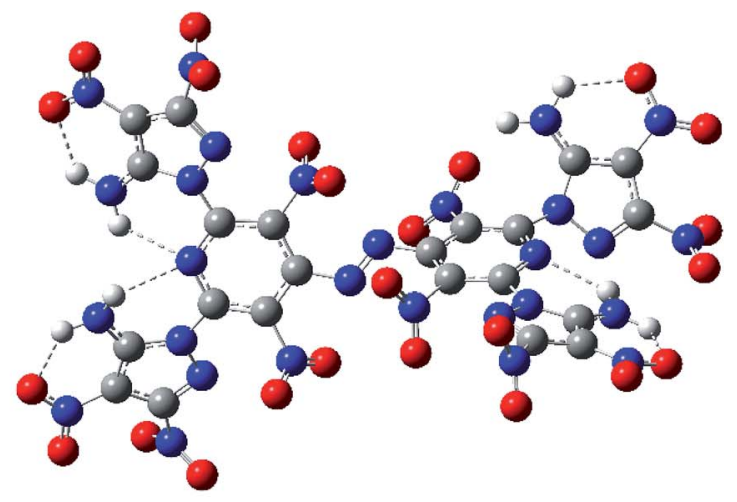

B10

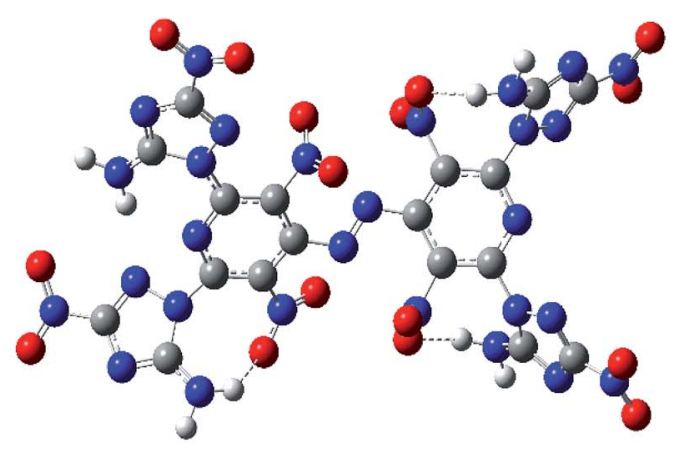

B12

Fig. 2 Spatial structures of representative compounds B9-B12. 
crucial effects on reaction mechanisms. Particularly, their energy gap can provide many useful information on optical polarizability, kinetic stability and chemical reactivity. ${ }^{8}$ The frontier molecular orbital energies and their energy gaps $\left(\Delta E_{\text {LUMO-номо }}\right)$ for designed compounds were listed in Table 1. For homologous bridged pyridine derivatives, it is found that HOMO energy levels increase evidently while $-\mathrm{NH}_{2}$ and $-\mathrm{NHNH}_{2}$ groups are introduced to the pyridine ring, so as LUMO energy levels. Oppositely, HOMO energy levels decrease when $-\mathrm{CN},-\mathrm{CH}\left(\mathrm{NO}_{2}\right)_{2},-\mathrm{C}\left(\mathrm{NO}_{2}\right)_{3}$ or 3,4,5trinitro- $1 \mathrm{H}$-pyrazole are attached, so as LUMO energy levels. Furthermore, HOMO and LUMO energy levels present no regularity when different bridges (such as $-\mathrm{CH}=\mathrm{CH}-,-\mathrm{NH}-$ $\mathrm{NH}-$ and $-\mathrm{N}=\mathrm{N}-$ ) are incorporated.

Fig. 1 (the HOMO-LUMO pictures are in ESI Table S1 $\dagger$ ) displays the variation trends of highest occupied orbital, lowest unoccupied molecular orbital energy levels and energy gaps of representative designed compounds B1, B2, B3, B4, B5, B8, B9, B12. It reveals that $\Delta E_{\text {Luмо-номо decreases }}$ evidently while 3,4-dinitro-1 $H$-pyrazol-5-amine (10), 3,5dinitro- $1 H$-pyrazol-4-amine (11), and 3-nitro- $1 H$-1,2,4-triazol5-amine (12) are incorporated for series A-F, whereas the addition of other groups or energetic compounds makes

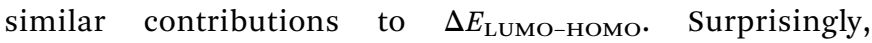
$\Delta E_{\mathrm{LUMO}-\mathrm{Hомо}}$ is demonstrated to be much higher when 3,4,5trinitro- $1 H$-pyrazole (9) was incorporated than that of other three energetic compounds (10-12), convincing that steric hindrance effect is a decisive factor for structural stability caused by a combination of amino and nitro groups (Fig. 2, see ESI Table $\mathrm{S} 2 \dagger)$. In general, $\Delta E_{\mathrm{Lu} \text { м-номо increases }}$ gradually as different bridges incorporated in order of $-\mathrm{N}=$ $\mathrm{N}-, \quad-\mathrm{NH}-\mathrm{NH}-, \quad-\mathrm{CH}=\mathrm{CH}-$. In view of all designed compounds, compound $\mathbf{F} 3$ has the highest $\Delta E_{\text {LUмо-номо }}$ of $4.61 \mathrm{eV}$ while compounds $\mathrm{B} 12$ has the smallest $\Delta E_{\mathrm{LUMO}}$-номо of $2.06 \mathrm{eV}$, showing that $\mathbf{F} 3$ is the most inactive and $\mathbf{B 1 2}$ is the most active under external stimulus.

$$
\begin{gathered}
\mathrm{CH}_{3} \mathrm{CH}\left(\mathrm{NO}_{2}\right)_{2}+2 \mathrm{CH}_{4} \longrightarrow \mathrm{CH}_{3} \mathrm{CH}_{3}+2 \mathrm{CH}_{3} \mathrm{NO}_{2} \\
\mathrm{CH}_{3} \mathrm{C}\left(\mathrm{NO}_{2}\right)_{3}+3 \mathrm{CH}_{4} \longrightarrow \mathrm{CH}_{3} \mathrm{CH}_{3}+3 \mathrm{CH}_{3} \mathrm{NO}_{2}
\end{gathered}
$$

Scheme 3 Isodesmic reactions for polynitromethane.

Table 2 HOF calculated for polynitromethane at G4 level

\begin{tabular}{lllll}
\hline Compd & $E_{0}{ }^{a}$ (a.u.) & $\begin{array}{l}\mathrm{ZPE}^{a} \\
\left(\mathrm{~kJ} \mathrm{~mol}^{-1}\right)\end{array}$ & $\begin{array}{l}H_{\mathrm{T}}{ }^{a} \\
\left(\mathrm{~kJ} \mathrm{~mol}^{-1}\right)\end{array}$ & $\begin{array}{l}\Delta H_{\mathrm{f}, \text { gas }} \\
\left(\mathrm{kJ} \mathrm{mol}^{-1}\right)\end{array}$ \\
\hline $\mathrm{CH}_{4}$ & -40.506540 & 117.5 & 10.0 & $-74.6^{b}$ \\
$\mathrm{CH}_{3} \mathrm{CH}_{3}$ & -79.808058 & 195.7 & 11.6 & $-84.0^{b}$ \\
$\mathrm{CH}_{3} \mathrm{NO}_{2}$ & -244.957724 & 130.7 & 14.0 & $-81.0^{b}$ \\
$\mathrm{CH}_{3} \mathrm{CH}_{\left(\mathrm{NO}_{2}\right)_{2}}$ & -488.711186 & 212.5 & 22.9 & $-105.1^{c}$ \\
$\mathrm{CH}_{3} \mathrm{C}\left(\mathrm{NO}_{2}\right)_{3}$ & -693.145352 & 216.1 & 29.3 & $-73.9^{c}$
\end{tabular}

${ }^{a}$ Calculated at the $\mathrm{G} 4$ level. ${ }^{b}$ Obtained from http://webbook.nist.gov.
${ }^{c}$ Obtained by isodesmic reaction.

\subsection{Heat of formation}

Heat of formation (HOF), calculated by atomization reaction or isodesmic reaction, is an important parameter in predicting detonation properties of energetic materials. Compounds $\mathrm{CH}_{3} \mathrm{CH}\left(\mathrm{NO}_{2}\right)_{2}$ and $\mathrm{CH}_{3} \mathrm{C}\left(\mathrm{NO}_{2}\right)_{3}$ were calculated via isodesmic reactions (Scheme 3) at $\mathrm{G} 4$ level (Table 2). Total energies, zero-point energies, and thermal corrections for the reference compounds using the isodesmic reactions (Scheme S1, see ESI $\dagger$ ) are listed in Table 3.

Table 4 presents the $\Delta H_{\mathrm{f}, \mathrm{gas}}, A, v,{\sigma_{\text {tot }}}^{2}, \Delta H_{\text {sub }}$ and $\Delta H_{\mathrm{f}, \text { solid }}$ of bridged pyridine derivatives. It is seen that all compounds have positive $\Delta H_{\mathrm{f}, \mathrm{gas}}$ range from to 142.8 (F4) to $1876.9 \mathrm{~kJ} \mathrm{~mol}^{-1}$ (B2). It reveals that energetic materials attached with $-\mathrm{N}_{3}$ group often have the highest $\Delta H_{\mathrm{f} \text {,solid, }}$ while $-\mathrm{NH}_{2},-\mathrm{CH}\left(\mathrm{NO}_{2}\right)_{2},-\mathrm{NHNO}_{2}$ groups are not conducive to

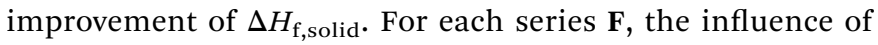
different energetic groups on $\Delta H_{\mathrm{f}, \text { solid }}$ can be described as the following order: $-\mathrm{N}_{3}>-\mathrm{CN}>3,4,5$-trinitro- $1 \mathrm{H}$-pyrazole $>3$ nitro- $1 \mathrm{H}$-1,2,4-triazol-5-amine $>3,5$-dinitro- $1 \mathrm{H}$-pyrazol-4amine $>3$,4-dinitro- $1 \mathrm{H}$-pyrazol-5-amine $>-\mathrm{NHNH}_{2}>-\mathrm{NF}_{2}>$ $-\mathrm{C}\left(\mathrm{NO}_{2}\right)_{3}>-\mathrm{NHNO}_{2}>-\mathrm{CH}\left(\mathrm{NO}_{2}\right)_{2}>-\mathrm{NH}_{2}$. Meanwhile, azo bridged pyridine derivatives usually have better HOFs than

Table 3 Calculated total energies $\left(E_{0}\right)$, zero-point energies (ZPE), thermal corrections $\left(H_{T}\right)$ and heats of formation (HOFs) of the refer-

\begin{tabular}{|c|c|c|c|c|}
\hline Compd & $E_{0}{ }^{a}$ (a.u.) & $\begin{array}{l}\mathrm{ZPE}^{b} \\
\left(\mathrm{~kJ} \mathrm{~mol}^{-1}\right)\end{array}$ & $\begin{array}{l}H_{\mathrm{T}}^{b} \\
\left(\mathrm{~kJ} \mathrm{~mol}^{-1}\right)\end{array}$ & $\begin{array}{l}\Delta H_{\mathrm{f}, \mathrm{gas}} \\
\left(\mathrm{kJ} \mathrm{mol}^{-1}\right)\end{array}$ \\
\hline $\mathrm{CH}_{4}$ & -40.541022 & 115.8 & 10.1 & $-74.6^{c}$ \\
\hline $\mathrm{NH}_{3}$ & -56.589815 & 89.1 & 10.1 & $-45.9^{c}$ \\
\hline $\mathrm{CH}_{3} \mathrm{NO}_{2}$ & -245.127760 & 128.9 & 11.7 & $-81.0^{c}$ \\
\hline $\mathrm{CH}_{3} \mathrm{CN}$ & -132.816078 & 117.4 & 12.0 & $74.0^{c}$ \\
\hline $\mathrm{CH}_{3} \mathrm{~N}_{3}$ & -204.186410 & 130.3 & 14.3 & $\begin{array}{c}293.4 \\
\text { (ref. 9) }\end{array}$ \\
\hline $\mathrm{CH}_{3} \mathrm{NF}_{2}$ & -294.351870 & 121.4 & 13.7 & $-98.0^{d}$ \\
\hline $\mathrm{CH}_{3} \mathrm{NH}_{2}$ & -95.908614 & 165.7 & 11.5 & $-23.5^{c}$ \\
\hline $\mathrm{CH}_{3} \mathrm{NHNO}_{2}$ & -300.491413 & 174.6 & 16.1 & $\begin{array}{c}-73.2 \\
\text { (ref. 10) }\end{array}$ \\
\hline $\mathrm{CH}_{3} \mathrm{NHNH}_{2}$ & -151.253386 & 211.3 & 13.5 & $94.5^{c}$ \\
\hline $\mathrm{CH}_{3} \mathrm{CH}\left(\mathrm{NO}_{2}\right)_{2}$ & -489.043812 & 210.0 & 23.0 & $-105.1^{e}$ \\
\hline $\mathrm{CH}_{3} \mathrm{C}\left(\mathrm{NO}_{2}\right)_{3}$ & -693.610990 & 213.7 & 29.4 & $-73.9^{e}$ \\
\hline $\mathrm{CH}_{3} \mathrm{~N}=\mathrm{NCH}_{3}$ & -189.363781 & 218.2 & 16.1 & $146.0^{d}$ \\
\hline $\mathrm{CH}_{3} \mathrm{NHNHCH}_{3}$ & -190.578383 & 282.9 & 17.1 & $\begin{array}{c}90.0 \\
\text { (ref. 11) }\end{array}$ \\
\hline \multirow{4}{*}{$\mathrm{CH}_{3} \mathrm{CH}=\mathrm{CHCH}_{3}$} & -157.306017 & 278.9 & 17.0 & $-10.8^{c}$ \\
\hline & -248.398244 & 229.8 & 13.8 & $\begin{array}{c}140.6 \\
\text { (ref. 12) }\end{array}$ \\
\hline & -226.304546 & 184.6 & 12.4 & $\begin{array}{c}177.4 \\
\text { (ref. 12) }\end{array}$ \\
\hline & -242.358564 & 155.0 & 11.9 & $\begin{array}{c}192.7 \\
\text { (ref. 13) }\end{array}$ \\
\hline
\end{tabular}
ence compounds

${ }^{a}$ Calculated at the B3LYP/def2-TZVPP level. ${ }^{b}$ Calculated at the B3LYP/ $6-311 \mathrm{G}(\mathrm{d}, \mathrm{p})$ level, and the scaling factor is 0.9888 for ZPE and 1.0062 for $H_{\mathrm{T}} \cdot{ }^{14}{ }^{c}$ Obtained from http://webbook.nist.gov. ${ }^{d}$ Calculated at G4 level. ${ }^{e}$ Obtained by isodesmic reaction. 
hydrazine or vinyl bridged compounds. This phenomenon may be caused by $\pi-\pi$ conjugated system and large amount of nitrogen content. Besides, these high positive HOFs make great contribution to increasing detonation properties such as detonation velocities and detonation pressures.

\subsection{Detonation property}

Detonation properties that related to oxygen balance (OB), density $(\rho)$, heat of detonation $(Q)$, detonation velocity $(D)$ and detonation pressure $(P)$ are summarized in Table 5. For a comparison, detonation properties of two well-known explosives 1,3,5-trinitro-1,3,5-triazinane (RDX) and 1,3,5,7tetranitro-1,3,5,7-tetrazocane (HMX) were also presented. It is seen that most of the designed compounds have negative $\mathrm{OB}$, and energetic materials attached with $-\mathrm{C}\left(\mathrm{NO}_{2}\right)_{3}$ group always have $\mathrm{OB}$ of nearly zero, proving that polynitro compounds contribute to good values of OB. Meanwhile, energetic materials attached with $-\mathrm{CN},-\mathrm{NH}_{2}$, or $-\mathrm{NHNH}_{2}$ group always have dissatisfied $\mathrm{OB}$, proving that cyano and amino compounds are not conducive to good oxygen balance. Bridged pyridine derivatives with different substituents were also found to have different $\rho, Q, D$ and $P$ values: values of $\rho$ range from $1.70(\mathbf{E 6}, \mathbf{F 6})$ to $2.11 \mathrm{~g} \mathrm{~cm}^{-3}$ (D3); values of $Q$ range from 1090.5 (D4) to $1769.2 \mathrm{cal} \mathrm{g}^{-1}$ (B3). Compound $\mathbf{F 1}$ has the smallest value of detonation velocity $\left(7.1 \mathrm{~km} \mathrm{~s}^{-1}\right)$ and detonation pressure (21.5 GPa), while Compound D8 has the highest value of detonation velocity $\left(9.77 \mathrm{~km} \mathrm{~s}^{-1}\right)$ and detonation pressure $(46.0 \mathrm{GPa})$, which is also better than that of RDX and HMX.

Fig. 3 displays variation trends of $\rho, Q, D$ and $P$ of designed compounds, in which Fig. 3a shows the influence of different energetic groups on density. It can be seen that

Table 4 Calculated molecular properties and heats of formation of the designed compounds

\begin{tabular}{|c|c|c|c|c|c|c|c|c|c|c|c|c|c|}
\hline \multicolumn{2}{|c|}{ 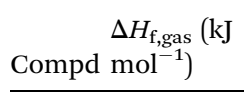 } & \multirow{2}{*}{$\begin{array}{l}\begin{array}{l}A \\
\left(\AA^{2}\right)\end{array} \\
361.4\end{array}$} & \multirow{2}{*}{$\frac{\nu}{0.1629}$} & \multirow{2}{*}{ 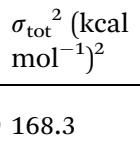 } & \multirow{2}{*}{$\begin{array}{l}\begin{array}{l}\Delta H_{\text {sub }}(\mathrm{kJ} \\
\left.\mathrm{mol}^{-1}\right)\end{array} \\
194.5\end{array}$} & \multirow{2}{*}{$\begin{array}{c}\begin{array}{l}\Delta H_{\mathrm{f}, \text { solid }}(\mathrm{kJ} \\
\left.\mathrm{mol}^{-1}\right)\end{array} \\
735.2\end{array}$} & \multirow{2}{*}{$\begin{array}{l}\text { Compc } \\
\text { D1 }\end{array}$} & \multirow{2}{*}{$\frac{\begin{array}{l}\Delta H_{\mathrm{f}, \mathrm{gas}}(\mathrm{kJ} \\
\left.\mathrm{mol}^{-1}\right)\end{array}}{1102.5}$} & \multirow{2}{*}{$\begin{array}{l}\begin{array}{l}A \\
\left(\AA^{2}\right)\end{array} \\
382.9\end{array}$} & \multirow{2}{*}{$\begin{array}{l}\nu \\
0.1418\end{array}$} & \multirow{2}{*}{$\begin{array}{l}\frac{\sigma_{\text {tot }}^{2}(\mathrm{kcal}}{\left.\mathrm{mol}^{-1}\right)^{2}} \\
268.6\end{array}$} & \multirow{2}{*}{$\begin{array}{l}\begin{array}{l}\Delta H_{\text {sub }}(\mathrm{kJ} \\
\left.\mathrm{mol}^{-1}\right)\end{array} \\
218.9\end{array}$} & \multirow{2}{*}{$\begin{array}{c}\begin{array}{l}\Delta H_{\mathrm{f}, \text { solid }}(\mathrm{kJ} \\
\left.\mathrm{mol}^{-1}\right)\end{array} \\
883.7\end{array}$} \\
\hline A1 & 929.7 & & & & & & & & & & & & \\
\hline A3 & 602.9 & 353.6 & 0.1600 & 141.1 & 184.9 & 418.1 & D3 & 467.3 & 387.8 & 0.0520 & 230.6 & 204.4 & 263.0 \\
\hline A4 & 471.3 & 336.8 & 0.2254 & 167.6 & 181.6 & 289.7 & D4 & 145.6 & 344.2 & 0.2484 & 233.9 & 197.4 & -51.8 \\
\hline A5 & 560.6 & 395.8 & 0.1514 & 139.3 & 219.2 & 341.5 & D5 & 339.4 & 455.4 & 0.1536 & 186.9 & 281.1 & 58.3 \\
\hline A8 & 687.8 & 477.7 & 0.0678 & 170.4 & 290.8 & 397.0 & D8 & 628.3 & 612.6 & 60.0363 & 230.8 & 451.6 & 176.7 \\
\hline A9 & 1178.8 & 586.4 & 0.1231 & 185.8 & 429.6 & 749.2 & D9 & 1616.9 & 836.3 & 30.0712 & 259.5 & 823.3 & 793.6 \\
\hline A10 & 971.9 & 553.6 & 0.1878 & 212.4 & 398.4 & 573.5 & D10 & 1216.5 & 762.0 & 00.1238 & 309.5 & 703.8 & 512.7 \\
\hline A11 & 984.5 & 554.5 & 0.2110 & 136.2 & 392.9 & 591.6 & D11 & 1217.2 & 765.3 & 30.2059 & 173.1 & 708.0 & 509.2 \\
\hline A12 & 1065.4 & 502.7 & 0.2232 & 275.0 & 348.9 & 716.5 & D12 & 1300.3 & 662.0 & 00.1805 & 276.2 & 550.8 & 749.5 \\
\hline B1 & 1296.9 & 407.9 & 0.1216 & 228.3 & 234.7 & 1062.2 & E1 & 721.7 & 362.8 & 80.1804 & 166.8 & 197.3 & 524.4 \\
\hline B6 & 891.6 & 417.0 & 0.2386 & 240.8 & 259.0 & 632.5 & E6 & 546.4 & 363.6 & 60.2475 & 215.8 & 210.5 & 335.8 \\
\hline B7 & 552.3 & 581.1 & 0.0696 & 260.6 & 419.1 & 133.2 & E7 & 347.6 & 442.0 & 00.1104 & 190.9 & 262.4 & 85.2 \\
\hline B8 & 806.7 & 630.5 & 0.0344 & 149.4 & 472.2 & 334.5 & E8 & 467.4 & 473.0 & 00.0801 & 188.2 & 289.2 & 178.2 \\
\hline B9 & 1814.7 & 846.4 & 0.0712 & 230.2 & 840.7 & 974.0 & E9 & 972.7 & 587.0 & 00.1287 & 185.3 & 431.1 & 541.6 \\
\hline B10 & 1409.3 & 787.7 & 0.1153 & 294.7 & 745.8 & 663.5 & E10 & 761.8 & 551.8 & 80.2108 & 199.5 & 397.3 & 364.5 \\
\hline B11 & 1405.2 & 785.0 & 0.1988 & 145.8 & 738.1 & 667.1 & E11 & 779.7 & 555.4 & 40.2176 & 132.8 & 394.1 & 385.5 \\
\hline B12 & 1516.2 & 682.2 & 0.1962 & 287.5 & 584.1 & 932.1 & E12 & 804.2 & 492.1 & 10.2362 & 212.1 & 331.8 & 472.4 \\
\hline C1 & 721.6 & 338.5 & 0.1841 & 168.0 & 178.8 & 542.8 & F1 & 1091.1 & 408.8 & 80.1271 & 247.8 & 237.9 & 853.2 \\
\hline C2 & 999.7 & 359.1 & 0.2373 & 107.7 & 191.4 & 808.4 & F2 & 1695.3 & 440.8 & 80.2272 & 116.2 & 265.0 & 1430.3 \\
\hline C3 & 397.5 & 343.4 & 0.1063 & 154.4 & 172.2 & 225.3 & F3 & 424.6 & 415.5 & 50.0629 & 186.3 & 228.9 & 195.7 \\
\hline $\mathrm{C4}$ & 259.5 & 324.5 & 0.2353 & 169.9 & 173.7 & 85.8 & F4 & 142.8 & 352.2 & 20.2493 & 251.6 & 205.7 & -62.8 \\
\hline C5 & 355.4 & 382.8 & 0.1629 & 163.8 & 211.8 & 143.6 & F5 & 322.2 & 462.1 & 10.1698 & 167.2 & 287.7 & 34.5 \\
\hline
\end{tabular}

${ }^{a}$ Calculated at the B3LYP/def2-TZVPP level. ${ }^{b}$ Calculated at the B3LYP/6-311G(d,p) level, and the scaling factor is 0.9888 for ZPE and 1.0062 for $H_{\mathrm{T}}{ }^{14}$ 
Table 5 Predicted densities $(\rho)$, heats of detonation $(Q)$, detonation velocities $(D)$

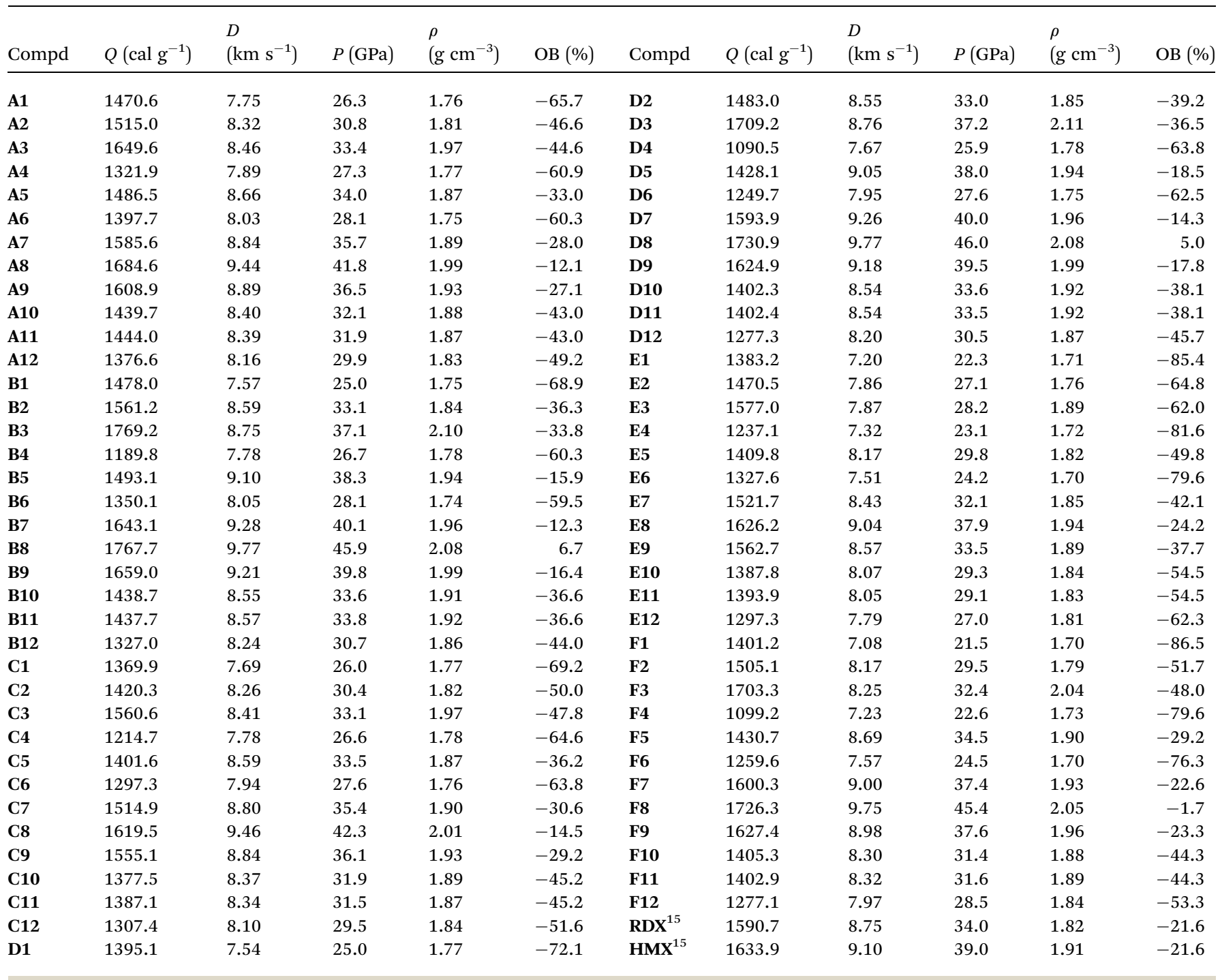

compounds substituted by $-\mathrm{NF}_{2}$ group have the highest density while $-\mathrm{CN},-\mathrm{NH}_{2}$ or $-\mathrm{NHNH}_{2}$ substituted ones have smaller density. Compounds with different bridged groups have similar values in detonation velocity, detonation pressure and density, indicating that $-\mathrm{CH}=\mathrm{CH}-,-\mathrm{NH}-\mathrm{NH}-$ and $-\mathrm{N}=\mathrm{N}$ - bridged groups have little effect in improving the values of $\rho, Q, D$ and $P$. Fig. $3 \mathrm{~b}$ shows the influence of different energetic groups on $Q$. It can be seen that compounds substituted by $-\mathrm{NF}_{2}$ and $-\mathrm{C}\left(\mathrm{NO}_{2}\right)_{3}$ group have the highest heat of detonation while $-\mathrm{NH}_{2},-\mathrm{NHNH}_{2}$ and 3nitro-1 $\mathrm{H}$-1,2,4-triazol-5-amine substituted ones have smaller heat of detonation. It is clearly seen that different bridged groups have different effects on $Q$ values in the order of $-\mathrm{N}=\mathrm{N}-,-\mathrm{CH}=\mathrm{CH}-,-\mathrm{CH}=\mathrm{CH}-$.

In view of Fig. $3 \mathrm{c}$ and $\mathrm{d}$, it is seen that the influence of different energetic groups on values of $D$ and $P$ were approximately the same throughout all series. The general influence order of different energetic groups on values of $D$ and $P$ can be described as follows: $-\mathrm{C}\left(\mathrm{NO}_{2}\right)_{3}>$ $-\mathrm{CH}\left(\mathrm{NO}_{2}\right)_{2} \approx 3,4,5$-trinitro- $1 \mathrm{H}$-pyrazole $>-\mathrm{NHNO}_{2}>-\mathrm{NF}_{2}$ $\approx-\mathrm{N}_{3} \approx 3,4$-dinitro- $1 H$-pyrazol-5-amine $\approx 3,5$-dinitro$1 H$-pyrazol-4-amine $>-\mathrm{NHNH}_{2}>-\mathrm{NH}_{2}>-\mathrm{CN}$ while the influence of different bridges on values of $D$ and $P$ can be described in the order of $-\mathrm{N}=\mathrm{N}-\approx-\mathrm{NH}-\mathrm{NH}->-\mathrm{CH}=$ $\mathrm{CH}-$. It can be concluded that polynitro groups are the most effective groups in improving $D$ and $P$ values while it is on the opposite side for insertion of $-\mathrm{CN},-\mathrm{NH}_{2}$ and $-\mathrm{NHNH}_{2}$.

\subsection{Thermal stability}

The bond dissociation energies (BDEs) are important in understanding thermal stability and enhancing controllability of kinetic energy release. In general, the smaller the energy is needed for breaking a bond, the weaker the bond is, and thus, this chemical bond may be acted as the trigger bond. The possible trigger bond with the weakest 

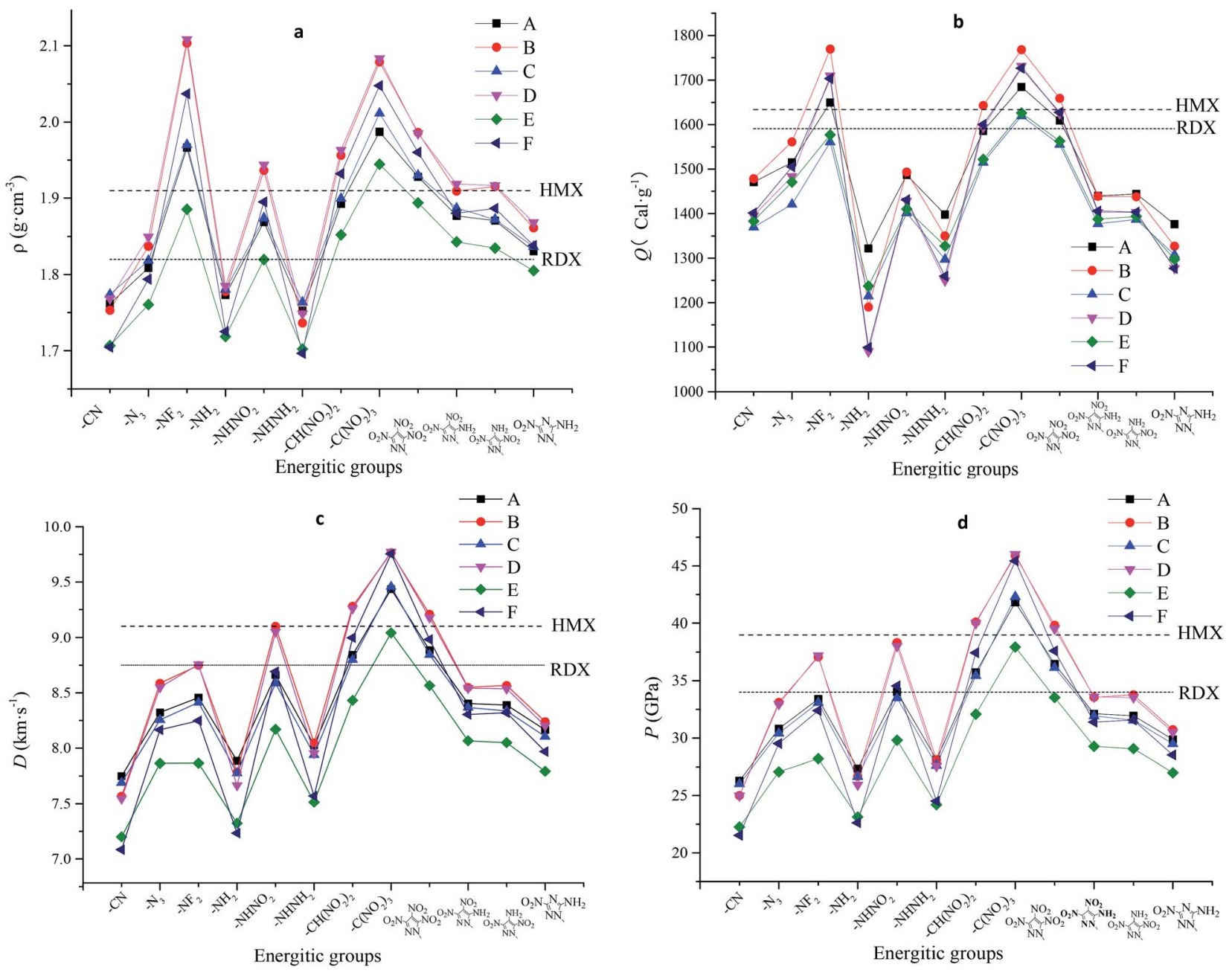

Fig. $3(a-d)$ Variation trends of $\rho, Q, D$ and $P$ of designed compounds.

BDE is selected as the breaking bond based on bond order analyses. The bond order and BDEs (specific data are shown in ESI Table S3 $\dagger$ ) of all designed compounds were summarized and listed in Table 6. In most cases, the possible trigger bond was likely $\mathrm{C}-\mathrm{NO}_{2}$ in 3- or 5-position of the pyridine ring (such as A1, A2, A9). In particular, when trinitromethyl or dinitromethyl was incorporated to the pyridine ring, $\mathrm{C}-\mathrm{N}$ bond in aliphatic carbon chain was weaker than that of aromatics (such as $\mathbf{A 7}, \mathbf{A 8}$ ). When $\mathrm{N}^{-}$ $\mathrm{NO}_{2}$ or $\mathrm{N}-\mathrm{NH}_{2}$ occurred, they both appeared to be the weakest bond in one curtain designed molecule. The nitrogen atom and fluorine atom both have strong ability to attract electron, making $\mathrm{N}-\mathrm{F}$ bond broken more easily. It is shocking that $\mathrm{N}-\mathrm{H}$ bond were known as the trigger bond in compound $\mathbf{A 4}$ and $\mathbf{B 4}$, for example, which were contradictory with the concept of increasing thermal stability by the use of an alternating array of amino and nitro-groups. The results show that a $\mathrm{p}-\pi$ conjugation effect formed between the nitrogen atom and pyridine ring, revealing that the nitrogen atom has the weaker ability to attract the hydrogen atom. The ultimate cause of this situation seems to have been the steric hindrance effect between four nitro groups directly attached to the pyridine ring. Besides, incorporating the bridge $-\mathrm{N}=\mathrm{N}-$ (series $\mathbf{A}$ and $\mathbf{B}$ ) or $-\mathrm{CH}=$ CH- (series $\mathbf{E}$ and $\mathbf{F}$ ) leads to the formation of $\pi-\pi$ conjugation between double bonds and the pyridine ring, so as to stabilize the bridged atoms.

\subsection{Thermal dynamic properties}

As the main contents of thermal dynamic parameters, standard molar heat capacity $\left(C_{\mathrm{p}, \mathrm{m}}^{\theta}\right)$, standard molar entropy $\left(S_{\mathrm{m}}^{\theta}\right)$ and standard molar enthalpy $\left(H_{\mathrm{m}}^{\theta}\right)$ can provide useful information in state equation, macroscopic properties and chemical reactions of energetic materials. ${ }^{16}$ The variation trends of $C_{\mathrm{p}, \mathrm{m}}^{\theta}, S_{\mathrm{m}}^{\theta}$ and $H_{\mathrm{m}}^{\theta}$ of designed compounds at different temperatures (every $10 \mathrm{~K}$ from $200 \mathrm{~K}$ to $600 \mathrm{~K}$, specific data are shown in ESI Table S4 $\dagger$ ) were investigated. The related equation for these parameters at different temperatures can be written in the following form: 
Table 6 Bond dissociation energies $\left(\mathrm{BDE}, \mathrm{kJ} \mathrm{mol}{ }^{-1}\right)$ for the weakest bonds

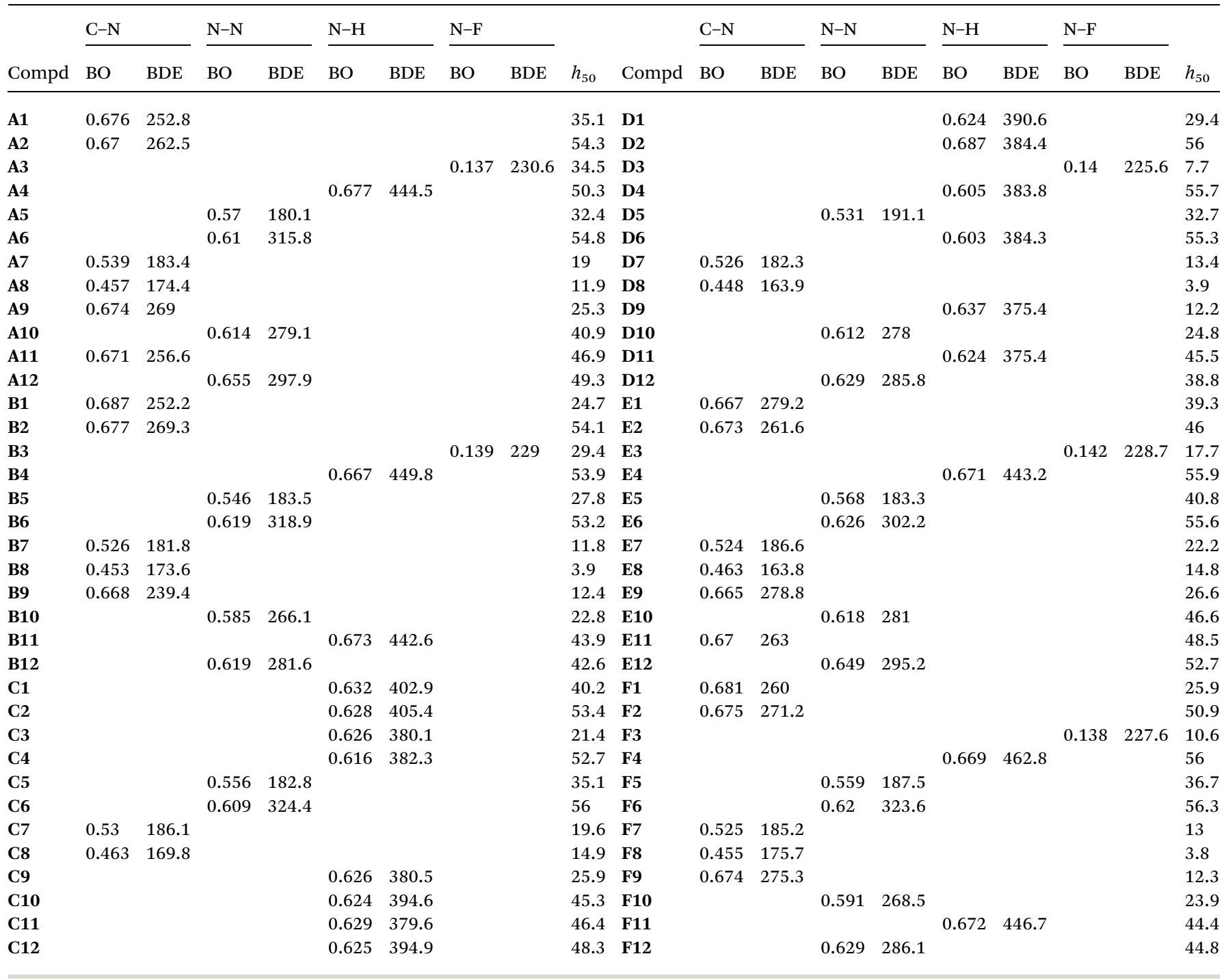

$$
X=a+b T+\operatorname{dis} c T^{2}\left(X=C_{\mathrm{p}, \mathrm{m}}^{\theta}, S_{\mathrm{m}}^{\theta} \text { and } H_{\mathrm{m}}^{\theta}\right)
$$

where $a, b$ and $c$ were constant and summarized in Table 7 . Take compound $\mathbf{A} 1$ and $\mathbf{A} 2$ for example, as can be seen from Fig. $4, C_{\mathrm{p}, \mathrm{m}}^{\theta}, S_{\mathrm{m}}^{\theta}$ and $H_{\mathrm{m}}^{\theta}$ of all designed compounds improved as the temperature increasing. However, there exists differences in the growth rates of these parameters. The case is that the growth rates $C_{\mathrm{p}, \mathrm{m}}^{\theta}, S_{\mathrm{m}}^{\theta}$ decreased evidently as the temperature increasing while growth rate of $H_{\mathrm{m}}^{\theta}$ increased. The reason is that the translations and rotations of chemical bonds were the main influencing factors at a low while vibrational movement occurred and intensified at a high temperature. At certain temperature, it is also found that the values of these thermal dynamic parameters increase as the volume of energetic groups increasing. This phenomenon may be caused by the strong space steric effects of energetic groups. For example, the $C_{\mathrm{p}, \mathrm{m}}^{\theta}, S_{\mathrm{m}}^{\theta}$ and $H_{\mathrm{m}}^{\theta}$ of compound $\mathbf{A} 7$ and $\mathbf{A 8}$ are $382.2 \mathrm{~J} \mathrm{~mol}^{-1} \mathrm{~K}^{-1}, 746.8 \mathrm{~J} \mathrm{~mol}^{-1} \mathrm{~K}^{-1}$,
$68.8 \mathrm{~kJ} \mathrm{~mol}^{-1}$ and $406.2 \mathrm{~J} \mathrm{~mol}^{-1} \mathrm{~K}^{-1}, 782.6 \mathrm{~J} \mathrm{~mol}^{-1} \mathrm{~K}^{-1}$, $73.2 \mathrm{~kJ} \quad \mathrm{~mol}^{-1}$, respectively (300k). Obviously, $C_{\mathrm{p}, \mathrm{m}}^{\theta}, S_{\mathrm{m}}^{\theta}$ and $H_{\mathrm{m}}^{\theta}$ of compound $\mathbf{A} 7$ are lower than those of compound $\mathbf{A 8}$.

The scaling factor is 0.9888 for ZPE, 1.0062 for variation of enthalpy from $0 \mathrm{~K}$ to $T$ and 1.0104 for entropy. ${ }^{\mathbf{1 4}}$

\subsection{Electrostatic potential}

Electrostatic potential (ESP), which provides meaningful insight into charge distributions and intermolecular interaction on the molecular surface of designed compounds were fully investigated. The ESP mapped surfaces and the surface areas of designed compounds were plotted in Fig. 5, where significant surface local minima and maxima of ESP are represented in blue and red, respectively. From Fig. 5, it is found that the positive potential (red areas) mainly concentrates on the parent skeleton while the negative 
Table 7 (Contd.)

\begin{tabular}{|c|c|c|c|c|c|c|c|c|c|c|}
\hline \multirow[b]{2}{*}{ Compd } & \multicolumn{3}{|l|}{$H_{\mathrm{m}}^{\theta}$} & \multicolumn{3}{|l|}{$S_{\mathrm{m}}^{\theta}$} & \multicolumn{3}{|l|}{$C_{\mathrm{p}, \mathrm{m}}^{\theta}$} & \multirow[b]{2}{*}{$R^{2}$} \\
\hline & $a$ & $b$ & $C \times 10^{-4}$ & $\mathrm{a}$ & $b$ & $C \times 10^{-4}$ & $a$ & $b$ & $C \times 10^{-4}$ & \\
\hline F3 & -19.10 & 0.24 & 4.39 & 372.18 & 2.17 & -8.16 & 90.36 & 1.71 & -10.30 & 0.9999 \\
\hline F4 & -15.95 & 0.16 & 4.34 & 279.41 & 1.73 & -5.40 & 24.56 & 1.63 & -9.41 & 0.9999 \\
\hline F5 & -17.51 & 0.24 & 5.28 & 408.60 & 2.31 & -7.90 & 75.88 & 1.93 & -10.90 & 0.9999 \\
\hline F8 & -36.86 & 0.43 & 7.30 & 411.23 & 3.74 & -14.50 & 187.82 & 2.77 & -16.30 & 0.9999 \\
\hline F9 & -35.17 & 0.47 & 9.22 & 597.80 & 4.37 & -16.00 & 207.33 & 3.30 & -18.20 & 0.9999 \\
\hline F10 & -34.88 & 0.42 & 9.16 & 498.70 & 4.07 & -14.20 & 148.64 & 3.33 & -18.60 & 0.9999 \\
\hline F11 & -36.47 & 0.42 & 9.23 & 462.29 & 4.06 & -14.00 & 136.87 & 3.38 & -19.10 & 0.9999 \\
\hline F12 & -27.23 & 0.33 & 8.00 & 444.36 & 3.32 & -10.90 & 89.91 & 2.89 & -16.10 & 0.9999 \\
\hline
\end{tabular}
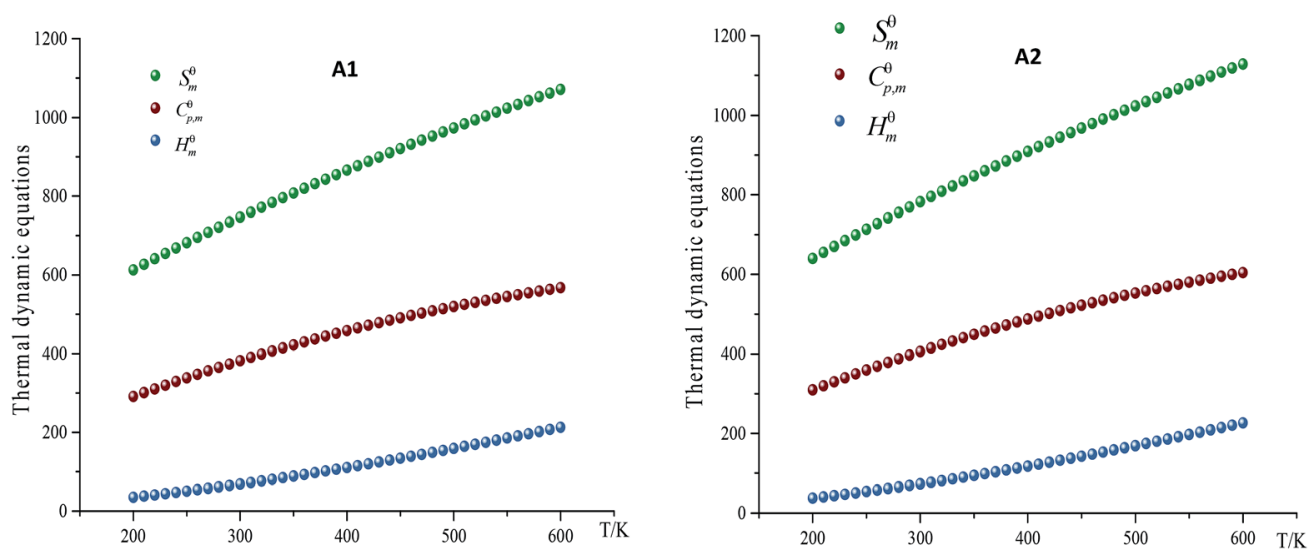

Fig. 4 Relationships between the thermodynamic equations and temperature for compound A1 and A2.

potential (blue areas) distributed mostly on the nitro groups and difluoramino groups, especially on the fluorine atom, which mainly due to its higher electronegativity. The positive areas of compounds B1, B2, B3, B4, B5, B8, B9 and B12 were calculated as $248 \AA^{2}$ (ratio 61\%), $251 \AA^{2}$ (ratio 57\%), $218 \AA^{2}$ (ratio 56\%), $180 \AA^{2}$ (ratio 51\%), $272 \AA^{2}$ (ratio 58\%), $398 \AA^{2}$ (ratio 63\%), $549 \AA^{2}$ (ratio 65\%), $426 \AA^{2}$ (ratio 62\%) respectively. As we can see that the positive regions are larger but also stronger in magnitude than the negative ones, which is consistent with Murray's research. ${ }^{17}$ Generally speaking, for organic molecules the negative regions cover a smaller portion of the total surface area but are significantly stronger (in terms of average magnitudes) than the positive ones. However, in the case of energetic molecules, the positive regions are not only larger but also stronger than the negative ones. From Table 6 , the $h_{50}$ values of compounds B1, B2, B3, B4, B5, B8, B9 and B12 were calculated as $24.7 \mathrm{~J}, 54.1 \mathrm{~J}$, $29.4 \mathrm{~J}, 53.9 \mathrm{~J}, 27.8 \mathrm{~J}, 3.9 \mathrm{~J}, 12.4 \mathrm{~J}, 42.6 \mathrm{~J}$ respectively. It is interesting to find that the surface electrostatic potentials of the less sensitive molecules do not differ dramatically from those of the others. The delocalization of the $\pi$ electronic charge that is such an important factor in stabilizing aromatic systems is counteracted in the nitroaromatics by the strongly electron-withdrawing effect of $\mathrm{NO}_{2}$ groups, which is reflected in the surface electrostatic potentials being positive rather than negative above the rings and in high degrees of internal charge separation..$^{18}$ As a result, positive areas of designed compounds were higher than negative areas which may stabilize the molecular structure.

\section{Conclusions}

In this work, a series of bridged pyridine energetic derivatives were designed and investigated by density functional theory method at DFT-D3(BJ)/B3LYP/6-311G(d,p) level. The results show that steric hindrance effect is a decisive factor for structural stability, and formation of intramolecular or intermolecular hydrogen bonds doesn't have advantages to stabilize molecular structure. The azide group and azo bridge can improve heats of formation of energetic pyridinebased materials. Compound $\mathbf{D 8}$ has the highest value of 


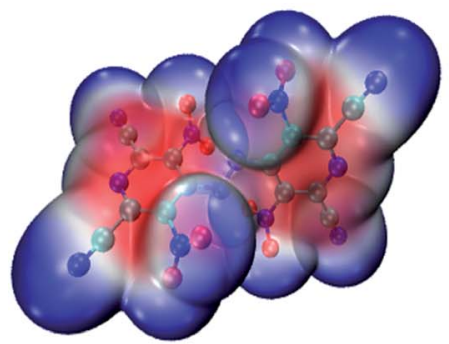

B1

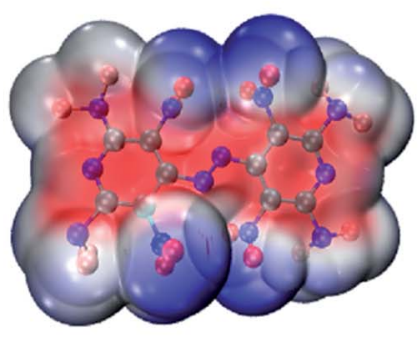

B3

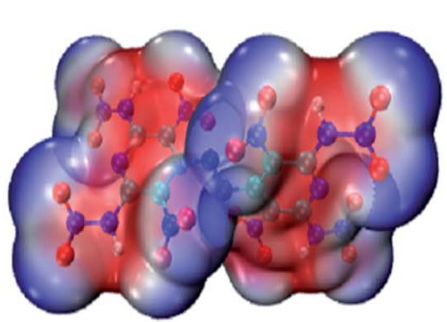

B5

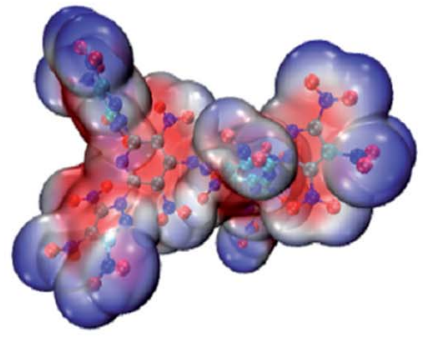

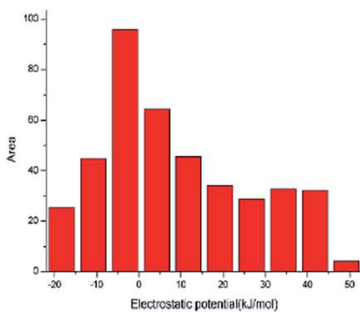
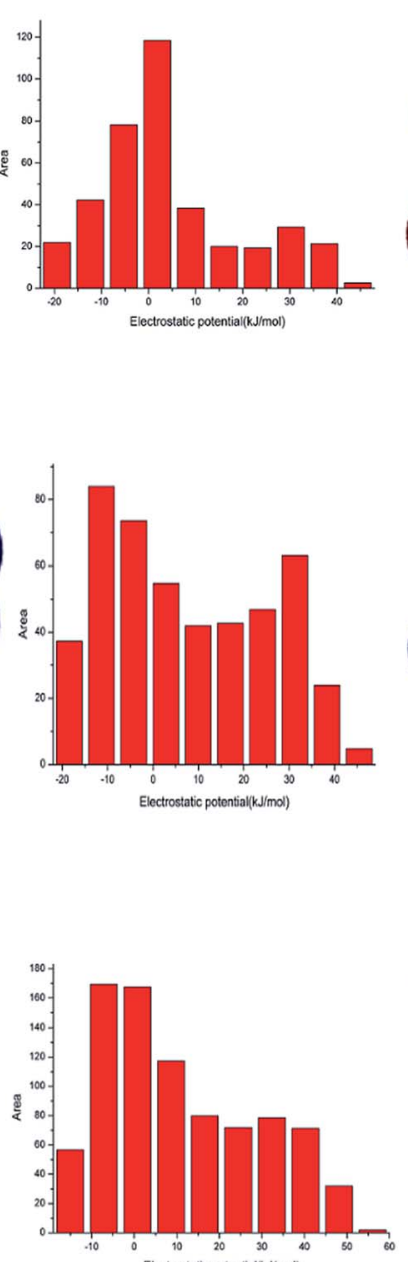

B9
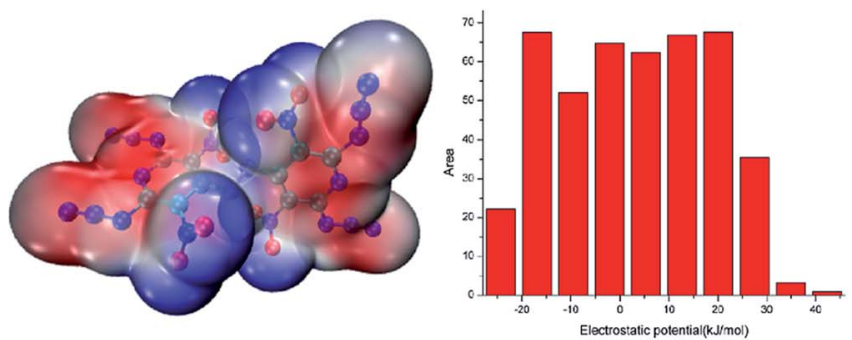

B2
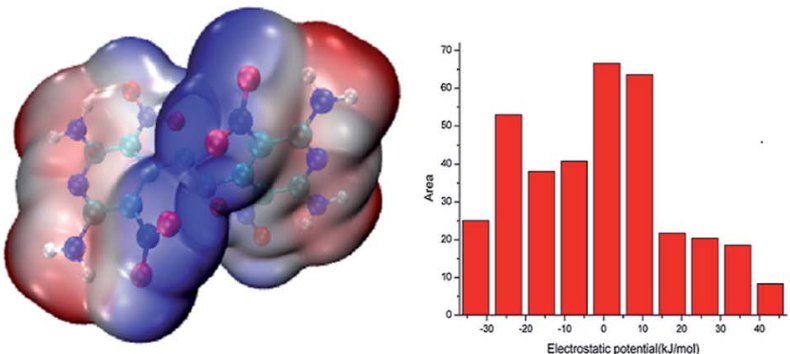

B4
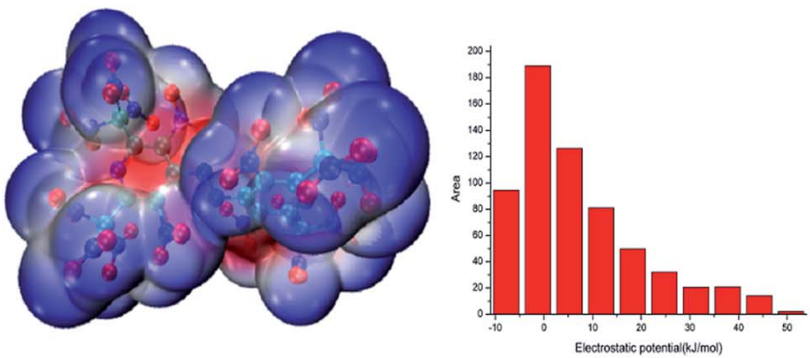

B8
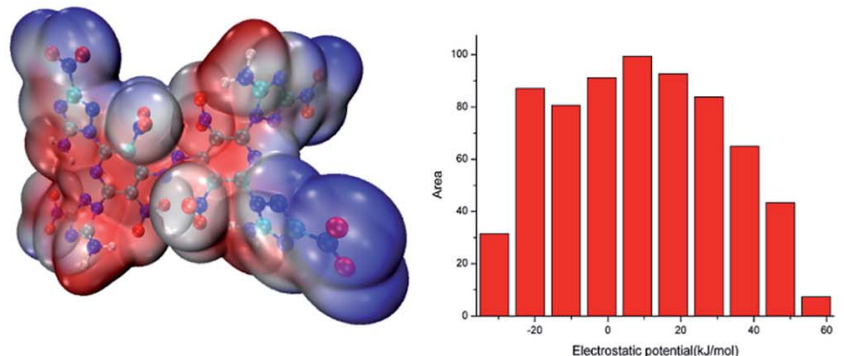

B12

Fig. 5 Electrostatic potential of representative designed molecules.

detonation velocity $\left(9.77 \mathrm{~km} \mathrm{~s}^{-1}\right)$ and detonation pressure (46.0 GPa), which is better than that of RDX and HMX, and can be selected as a potential candidate of promising high energy density materials. Analysis of the bond dissociation energies suggests that When a $\mathrm{p}-\pi$ conjugation formed between the nitrogen atom and pyridine ring, the bond between nitrogen and hydrogen atoms may be broken as the trigger bond.

\section{Conflicts of interest}

There are no conflicts of interest to declare.

\section{Acknowledgements}

This study was supported by the National Natural Science Foundation of China (No. 11702129). We are so grateful to the 
High Performance Computing Center of Nanjing Tech University for doing the numerical calculations in this paper on its $\mathrm{x}$ Flex enterprise blade cluster system.

\section{Notes and references}

1 P. F. Pagoria, G. S. Lee, A. R. Mitchell and R. D. Schmidt, Thermochim. Acta, 2002, 384, 187-204.

2 M. A. Hiskey, N. Goldman and J. R. Stine, J. Energ. Mater., 1998, 16, 119-127.

3 H. H. Licht and H. Ritter, Propellants, Explos., Pyrotech., 1988, 13(1), 25-29.

4 H. Ritter and H. H. Licht, J. Heterocycl. Chem., 1995, 32, 585590.

5 K. Zhao, Z. L. Liu and C. M. Ma, Chin. J. Energy Mater., 2015, 23, 1099-1102.

6 C.-M. Ma, Z. L. Liu and Q. Z. Yao, Chin. J. Energy Mater., 2015, 23, 1176-1180.

7 Y. Chen, H. X. Hao, S. Y. Xu and W. F. Zheng, J. Ordnance Equip. Eng., 2017, 38(6), 125-134.
8 A. Stobiecka, M. Sikora, R. Bonikowski and J. Kula, J. Mol. Struct., 2016, 1107, 82-90.

9 K. E. Gutowski, R. D. Rogers and D. A. Dixon, J. Phys. Chem. B, 2007, 111, 4788-4800.

10 E. A. Miroshnichenko, T. S. Kon'kova and Y. N. Matyushin, Dokl. Phys. Chem., 2003, 392, 253-255.

11 Á. Furka, Struct. Chem., 2009, 20, 605-616.

12 W. N. Hubbard, F. R. Frow and G. Waddington, J. Phys. Chem., 1961, 65, 1326-1328.

13 P. Jiménez, M. V. Roux and C. Turrión, J. Chem. Thermodyn., 1989, 21, 759-764.

14 J. P. Merrick, D. Moran and L. Radom, J. Phys. Chem. A, 2007, 111, 11683-11700.

15 M. B. Talawar, R. Sivabalan, T. Mukundan, H. Muthurajan, A. K. Sikder, B. R. Gandhe and A. S. Rao, J. Hazard. Mater., 2009, 161, 589-607.

16 J. Zhang and H. Xiao, J. Chem. Phys., 2002, 116, 10674-10683.

17 J. S. Murray, P. Lane and P. Politzer, Mol. Phys., 1998, 93, 187-194.

18 J. S. Murray, P. Lane and P. Politzer, Mol. Phys., 1995, 85, 1-8. 